\title{
Influence of different modes of application of chlorexidine digluconate on bond strength of universal adhesive system to dentin
}

\begin{abstract}
The aim was to evaluate the influence of different modes of application of chlorhexidine digluconate in the preservation of bond strength of universal adhesive system to dentin. Teeth were divided into 3 groups: Distilled water: (control), CHX PT: pre-treatment with $2 \%$ chlorhexidine digluconate and $\mathrm{CHX}+\mathrm{SBU}: 2 \%$ chlorhexidine digluconate incorporated into the adhesive system. All groups used the Universal adhesive system. After 24 hours, there was no statistical difference between the groups $(\mathrm{p}>0.05)$. After 6 months, a significant reduction in the bond strength of the control group was observed when compared to the CHX PT and CHX+SBU $(\mathrm{p}<0.05)$. The CHX PT and CHX+SBU maintained the bond strength over time as compared to the 24 hours values $(\mathrm{p}>0.05)$. It was concluded that the application of $2 \%$ chlorhexidine digluconate, through treatment or incorporated, maintained the bond strength of a universal adhesive system to dentin over time.
\end{abstract}

Keywords: bond strength, chlorhexidine, adhesive system

\author{
Volume II Issue 2 - 2020 \\ Gina Deborah Maia de Carvalho,' Marianny \\ Flexa Feitosa,' Bruna Dantas Muniz,' Lara \\ Rabelo Aragão, ${ }^{2}$ Taira Endi de Flaviano \\ Albuquerque, ${ }^{2}$ Phillipe Nogueira Barbosa \\ Alencar, ${ }^{1,2}$ Jiovanne Rabelo Neri ${ }^{1,2}$ \\ 'Graduate School of Dentistry, University of Fortaleza \\ (UNIFOR), Brazil \\ ${ }^{2}$ Nucleus of Study and Research in Dental Biomaterials \\ (NEPBiO), Graduate School of Dentistry, University Center of \\ Christus (UNICHRITUS), Brazil
}

\begin{abstract}
Correspondence: Phillipe Nogueira Barbosa Alencar, Graduate School of Dentistry, University of Fortaleza (UNIFOR), Washington Soares Avenue 1321, 608 I I-905, Fortaleza, Ceará, Brazil and Nucleus of Study and Research in Dental Biomaterials (NEPBiO), Graduate School of Dentistry, University Center of Christus (UNICHRITUS), João Adolfo Gurgel 133, 60190-060, Fortaleza, Ceará, Brazil,Tel +5585 32658100,Email dphillipnogueira@hotmail.com
\end{abstract}

Received: March 04, 2020 | Published: March 10, 2020

\section{Introduction}

The restorative dentistry evolved a lot in the past years with the improvement of techniques and adhesive materials. However, the dentin substrate adherence is still considered a major challenge. ${ }^{1}$ The presence of fluids within dentinal tubules, the regional variation of the dentine and the presence of collagen make critical the performance of adhesive procedures in the substrate. These variable are related to failure of the adhesive restorations through the marginal maladaptation and the reduction of the tooth-restoration union. ${ }^{2}$

The hybrid layer is an interface formed from the bond between resinous monomers of the adhesive and dentin, ${ }^{3}$ which is constantly exposed to hydrolytict ${ }^{4}$ and enzymatic degeneration, ${ }^{5}$ therefore jeopardizing the restorative procedures success. The enzymatic degradation occurs through theactivity of matrix metalloproteinases (MMPs), present in the dentinal tissue in inactive condition. ${ }^{6}$ After the demineralization, by the carious process or by the application of acid conditioning, the MMPs are activated and they will act in the collagen fibrils of the hybrid layer. ${ }^{5}$

In view of the need to increase the longevity of the restorations longevity, different methods to prevent the degradation of the hybrid layer have been researched. ${ }^{5,7,8-10}$ Amongst these techniques it is the utilization of forming agents of crosslinking in collagen (crosslinkers), increasing their mechanical properties and hindering the enzymatic action. ${ }^{7}$ Another way to hinder the hybrid layer degradation is the biomimetic remineralization of the dentin, when the spaces in the dentin are filled by hydroxyapatite crystals, reducing the amount of water between the collagen fibrils. ${ }^{8}$ On the other hand, ethanol has the function of decreasing the fluid between the collagen fibrils and provides a greater space between them, allowing a greater amount of resin to penetrate the substrate. ${ }^{9}$ Other significative manner of preserving the interdiction zone between the adhesive and the dentine is through the use of chlorhexidine digluconate, which acts inhibiting the action of matrix metalloproteinases. ${ }^{5,10-12}$

Chlorhexidine $(\mathrm{CHX})$ is a very potent antimicrobial agent, used constantly in dental procedures. ${ }^{13}$ In addition, studies prove that the chlorhexidine even in their lower concentration, acts like an inhibitor of the enzymes responsible for degradation of the interface of the resin-substrate union, ${ }^{10,14}$ through the mechanism of calcium and zinc ion chelation. This enzymatic inhibitor takes the free calcium and zinc ions and make them unavailable for the MMPs, therefore inhibiting their activity. Thus, the use of chlorhexidine after the dentine acid conditioning and before the application of the adhesive system results in the preservation of the resistance of tooth-restoration union. ${ }^{15,16}$

The purpose of this study was to evaluate the influence of different application manners of chlorhexidine digluconate in the preservation of the resistance of the adhesive systems union to dentine. The null hypotheses were:

1. There won't be statistic difference amongst the union resistance values in 24 hours period.

2. There won't be statistic difference amongst the union resistance values passed six months of storage. 


\section{Material and methods}

\section{Preparation of solutions}

Chlorhexidine digluconate (Sigma-Aldrich, St. Louis, MO, USA) was diluted in distilled water to obtain a aqueous solution at $2 \%(\mathrm{v} / \mathrm{v})$ or incorporated into the commercial Single Bond Universal $(3 \mathrm{M}$ ESPE, St. Paul, MN, USA) at concentration of $2 \%$.

\section{Preparation of samples}

Fifteen unerupted third molars were collected after the patients informed consent had been obtained under a protocol reviewed and approved by the local Ethics Committee (\#1.819.455). Selected teeth were stored in $0.1 \%$ thymol solution and used within one month after extraction

Occlusal surfaces of all teeth were removed using a \#180-grit silicon carbide $(\mathrm{SiC})$ paper mounted to an electric polishing machine (APL 4, Arotec, Cotia, SP) to expose a flat coronal dentin surface. The dentin surface was prepared with \#600-grit $\mathrm{SiC}$ paper under copious water for 60 seconds to standardize the smear layer. The teeth were randomly allocated by the Excel software (Excel 2013, Microsoft Corporation, Redmond, WA, USA) into 3 groups $(n=5)$ according to the treatement used (Table 1).

Table I Experimental design

\begin{tabular}{lll}
\hline Group & Treatment & Adhesive system \\
\hline $\begin{array}{l}\text { Distilled } \\
\text { water } \\
\text { (control) }\end{array}$ & Distilled water & Single Bond Universal \\
& $\begin{array}{l}\text { Aqueous solution } \\
\text { of 2\% digluconate } \\
\text { chlorhexidine }\end{array}$ & Single Bond Universal \\
CHX PT & Distilled water & $\begin{array}{l}\text { Single Bond Universal doped } \\
\text { with 2\% chlorhexidine } \\
\text { digluconate }\end{array}$ \\
$\mathrm{CHX}+\mathrm{SBU}$ & &
\end{tabular}

The exposed dentin surfaces of all teeth were etched with $37 \%$ phosphoric acid gel (Condac37; FGM Produtos Odontológicos Ltda., Joinville, SC, Brazil) for $15 \mathrm{~s}$, rinsed for $30 \mathrm{~s}$ with distilled water, and dried with oil-/water-free air for $10 \mathrm{~s}$. The teeth were re-hydrated with $50 \mu \mathrm{L}$ of with the solutions predetermined for each group (Table 1). The solutions were rubbed on the surface with a microbrush for $60 \mathrm{~s}$, and excess of each solution removed with absorbent paper, leaving the dentin surface visibly moist. The adhesive system Single Bond Universal (3M ESPE, St. Paul, MN, USA) was applied according to manufacturer's instructions (Table 2). After light curing the adhesive (Poly Wireless; Kavo ${ }^{\circledR}$, Joinvile, SC, Brazil), five $1 \mathrm{~mm}$ thick increments of composite resin were built up (Filtek Z350XT; 3M ESPE, St. Paul, MN, USA ). Each increment was light-cured (Poly Wireless) for $20 \mathrm{~s}$, with a power density of $1000 \mathrm{~mW} / \mathrm{cm} 2$. The bonded teeth were stored in distilled water at $37^{\circ} \mathrm{C}$ for $24 \mathrm{~h}$ (Table 2).

After storage, the bonded teeth were longitudinally sectioned in both " $\mathrm{x}$ " and " $\mathrm{y}$ " directions across the bonded interface using a diamond saw in a Isomet (Buehler, Lake Bluff, IL, USA) under water cooling to obtain bonded sticks with cross-sectional area of approximately $1.0 \mathrm{~mm} 2$. The cross-sectional area of each stick was measured with a digital caliper (Absolute Digimatic, Mitutoyo,
Tokyo, Japan) to the nearest $0.01 \mathrm{~mm}$ and recorded for subsequent calculation of bond strength values.

Table 2 Adhesive system and bonding procedure

\begin{tabular}{|c|c|c|c|}
\hline Product & Composition & $\begin{array}{l}\text { Manufacturer } \\
\left(\# B a t c h n^{\circ}\right)\end{array}$ & $\begin{array}{l}\text { Application } \\
\text { mode }\end{array}$ \\
\hline \multirow[t]{2}{*}{$\begin{array}{l}\text { Single Bond } \\
\text { Universal }\end{array}$} & $\begin{array}{l}\text { MDP, BIS-GMA HEMA, } \\
\text { DMA, methacrylate } \\
\text { functional copolymer, } \\
\text { filler, ethanol, water, } \\
\text { initiators, silane }\end{array}$ & $\begin{array}{l}\text { 3M ESPE, } \\
\text { St.Paul, } \\
\text { MN, USA } \\
(\#|5| 8000 \mid 70)\end{array}$ & $\begin{array}{l}\text { Apply the } \\
\text { adhesive }\end{array}$ \\
\hline & & & $\begin{array}{l}\text { Allow it to } \\
\text { react for } 20 \mathrm{~s} \\
3 . \text { Gently air } \\
\text { dry for } 5 \mathrm{~s}\end{array}$ \\
\hline
\end{tabular}

Abreviations: MDP, 10-methacryloyloxydecyl dihydrogen phosphate; BIS-GMA, bisphenol A diglycidyl methacrylate; HEMA, 2-hydroxyethyl methacrylate; DMA, dimethacrylate Sticks from each tooth were randomly allocated by the Excel software (Excel 2013, Microsoft Corporatin, One Microsoft Way, Redmond, WA, USA) and assigned to three storage times: 24 hours and 6 months. All sticks were stored in distilled water at $37^{\circ} \mathrm{C}$ and the storage solution was changed every two weeks.

\section{MTBS test}

Each bonded stick was attached with cyanoacrylate glue (Super Bonder Gel, Loctite, São Paulo, SP, Brazil) to a modified Geraldeli testing apparatus (Odeme Biotechnology, Joaçaba, SC, Brazil) and subjected to a tensile force at $1.0 \mathrm{~mm} / \mathrm{min}$ in a universal testing machine (Instron 3345; Instron Inc., Canton, MA, USA). The load at fracture was used to calculate bond strength $(\mathrm{MPa})$.

The failure mode was evaluated using a stereoscope at $40 \mathrm{X}$ magnification (Stemi 305 Stereo Microscope, Zeiss, Oberkochen, Germany), and classified as cohesive when fracture occurred exclusively within dentin (CD) or resin composite (CR); adhesive (A) when was at the dentin/resin interface, or mixed (M) when two modes of failure (adhesive and cohesive) occurred simultaneously.

\section{Statistical analysis}

Statistical procedures were performed with the Sigmastat 3.5 (Systat Software Inc., San Jose, CA, USA) for Windows statistical program software. A Shapiro-Wilk test was applied to all groups to analyze the normal distribution of errors and the Barllet test for the homoscedasticity. Bond strength values were statistically analyzed with Two-way ANOVA (treatment and storage time) and StudentNewman-Keuls method was used for post hoc comparisons. Statistical significance was set at $p<0.05$. Teeth were used as a statistical unit and the number of prematurely debonded specimens was recorded, although this was not included in the analysis.

\section{Results}

The bond strength data are shown in the Table 3. The results were not affected by treatment $(\mathrm{p}=0.135 ; \mathrm{F}=2,181)$, however, were affected by storage time $(\mathrm{p}<0.001 ; \mathrm{F}=14,267)$. Interactions were not statistically significant ( $\mathrm{p}=0.108 ; \mathrm{F}=2,446)$. After 24 hours, there was no statistical difference between the groups tested $(\mathrm{p}>0.05)$. After 
6 months, a significant reduction in the bond strength values of the distilled water group (control) was observed when compared to the CHX PT $(p=0.016)$ and $\mathrm{CHX}+\mathrm{SBU}(\mathrm{p}=0.035)$ groups. The CHX PT and $\mathrm{CHX}+\mathrm{SBU}$ groups maintained the bond strength over time as compared to the 24 hours values $(\mathrm{p}>0.05)$. In contrast, the control group significantly reduced the bond strength values after 6 months when compared to the 24 hours ( $\mathrm{p}=0.001$ ) (Table 3 ).

Table 3 Bond strength values (MPa \pm SD $(*))$ according to adhesive systems used

\begin{tabular}{lll}
\hline Groups $(\mathbf{n}=\mathbf{5})$ & \multicolumn{2}{l}{ Storage Times } \\
\cline { 2 - 3 } & $\mathbf{2 4}$ hours & $\mathbf{6}$ months \\
\hline $\begin{array}{l}\text { Distilled water } \\
\text { (control) }\end{array}$ & $23.55 \pm 4.30(32)^{\mathrm{A}, \mathrm{a}}$ & $16.77 \pm 6.10(37)^{\mathrm{A}, \mathrm{b}}$ \\
$\mathrm{CHX}$ PT & $24.56 \pm 6.66(46)^{\mathrm{B}, \mathrm{a}}$ & $26.53 \pm 5.99(45)^{\mathrm{A}, \mathrm{b}}$ \\
$\mathrm{CHX}+\mathrm{SBU}$ & $24.72 \pm 4.45(34)^{\mathrm{A}, \mathrm{a}}$ & $25.48 \pm 5.50(32)^{\mathrm{A}, \mathrm{b}}$ \\
\hline
\end{tabular}

Identical superscript letters indicate no statistical significance between values Capital letters compare treatments and lower cases compare storage time. $\left({ }^{*}\right)$ corresponds to the number of sticks tested per group in each period

Table 4 shows the percentage of fracture modes of the specimens. Most failures were mixed in all tested groups at all storage times. At 24 $\mathrm{h}$, adhesive failures were more common than cohesive failures (resin and dentin) for specimens of all groups. The number of adhesive and premature failures increased with ageing, mainly in the control group (Table 4).

Table 4 Distribution of mode of fracture of each group expressed as $n$ (relative percentage)

\begin{tabular}{|c|c|c|c|c|c|c|c|c|c|c|}
\hline \multirow{3}{*}{ Groups } & \multicolumn{10}{|c|}{ Single bond universal } \\
\hline & \multicolumn{5}{|c|}{24 hours } & \multicolumn{5}{|c|}{6 months } \\
\hline & A & M & CR & CD & PF & A & $\mathbf{M}$ & CR & CD & PF \\
\hline \multirow[t]{2}{*}{$\begin{array}{l}\text { Distilled } \\
\text { water } \\
\text { (control) }\end{array}$} & 5 & 27 & 0 & 2 & 1 & 12 & 25 & 2 & 2 & 10 \\
\hline & 14 & 77 & 0 & 6 & 3 & 23 & 49 & 4 & 4 & 20 \\
\hline \multirow[t]{2}{*}{ CHX PT } & 7 & 39 & 3 & 2 & 1 & 7 & 38 & 2 & 0 & 5 \\
\hline & 13 & 75 & 6 & 4 & 2 & 13 & 73 & 4 & 0 & 10 \\
\hline \multirow[t]{2}{*}{$\begin{array}{l}\mathrm{CHX}+ \\
\mathrm{SBU}\end{array}$} & 4 & 30 & 2 & 3 & 1 & 3 & 29 & 5 & 1 & 4 \\
\hline & 10 & 75 & 5 & 7 & 3 & 7 & 69 & 12 & 2 & 10 \\
\hline
\end{tabular}

$A$, adhesive failure; $M$, mixed failure; $C R$, cohesive failure in resin; $C D$, cohesive failure in dentin; PF, premature failure

\section{Discussion}

Chlorhexidine is a chemical with antibacterial action, presenting broad spectrum against gram-positive and gram-negative bacteria. ${ }^{18}$ The use of this antiseptic has been indicated as auxiliary, after the removal of the carious tissue and before the adhesive systems application, as a strategy to prevent caries. ${ }^{19}$ The action mechanism of chlorhexidine is explained through the interaction between the chlorhexidine positive (cationic) molecule and the negative cell wall of the bacterium, that modifies the morphology and amplifies the bacterial permeability, enabling the chlorhexidine to reach the interior of the cell. Therefore, the osmotic balance is lost, resulting in the cell death. ${ }^{20}$

Studies prove that the use of chlorhexidine digluconate by $2 \%$ does not impair the immediate bond strength of adhesive systems to dentine, either as pretreatment ${ }^{16,21,22}$ or when incorporated into the union agents. ${ }^{25}$ These findings corroborate with the results of the present study (Table 3).

Adhesive systems are responsible for bonding the restorative material to the dentine structures. However, the resin-dentine union interface is more vulnerable to degradation than to enamel. ${ }^{17}$ This happens, mainly, due to the permeability of the hybrid layer, which is susceptible to degradation of collagen fibrils through the enzymatic activity of metalloproteinases (MMP's) and cysteine cathepsins (CTs). ${ }^{17,26}$ Thus, strategies that may inhibit the effect of MMPs and CTs have been of great importance for the prevention of dentine-resin union interfaces. ${ }^{10,26}$

Chlorhexidine digluconate has the ability to inhibit the action of MMPs 2 and 9, and CTs (cysteines cathepsins) B, L and K. ${ }^{27,28}$ It acts through the interaction between its positive (cationic) molecule with the calcium and zinc ions, which are fundamental for the enzymatic activity. The findings of the present study showed that the use of chlorhexidine associated with a universal adhesive system was efficient in maintaining the union resistance over time (Table 3). Beside the inhibitory action of MMPs, possibly, by applying the chlorhexidine digluconate over the dentine substrate, an increase of the free energy of the pretreated surface by the phosphoric acid will be achieved, thus improving the union resistance., 92,26

Stanislawexuk et al. ${ }^{23}$ analyzed the consequences of the use of CHX by $2 \%$ added to phosphoric acid and in an immediate aqueous solution after 6 months. They concluded that there was preservation of the resin-dentine interface durability. Thus, it is possible to verify the efficiency of the chlorhexidine when applied on the dentine, considering that it can prevent the degradation of the collagen fibrils..$^{5,22}$

Some studies have observed that the application of chlorhexidine digluconate associated with self-etch adhesive systems did not promote promising results. ${ }^{25}$ The interaction between chlorhexidine and the dentin substrate reduces the bonding capacity of the resinous monomers of the self-etch systems with hydroxyapatite..$^{30}$ Thus, it is possible to speculate that the effect of chlorhexidine on maintaining the stability of union interfaces to dentin is dependent on the adhesive system used. An important parameter to be observed is the clinical behavior of compound resin restorations performed on dentin substrate by the application of chlorhexidine, which is a limitation of the present study. Therefore, future studies should be performed to evaluate the efficiency of chlorhexidine digluconate associated with universal adhesive systems under clinical conditions.

\section{Conclusion}

The application of $2 \%$ chlorhexidine digluconate, by treatment or incorporated, maintained the bond strength of a universal adhesive system to dentin over time.

\section{Funding}

None. 


\section{Acknowledgments}

None.

\section{Conflicts of interest}

The authors declare that there are no conflicts of interest.

\section{References}

1. Reis AF, Giannini M, Pereira PN. Effects of a peripheral enamel bond on the long-term effectiveness of dentin bonding agents exposed to water in vitro. J Biomed Mater Res Part B: Applied Biomaterials. 2008;85B:10 17.

2. Martins GC, Franco APGO, Godoy EDP, et al. Dentin adhesives. $R G O$. 2008;56:429-436.

3. Nakabayashi N, Kojima K, Masuhara E. The promotion of adhesion by the infiltration of monomers into tooth substrates. J Biomed Mater Res. 1982;16(3):265-273.

4. De Munck J, Van den Steen PE, Mine A, et al. Inhibition of enzymatic degradation of adhesive-dentin interfaces. J Dent Res. 2009;88(12):11011106.

5. Pashley DH, Tay FR, Yiu C, et al. Collagen degradation by host-derived enzymes during aging. J Dent Res. 2004;83(3):216-221.

6. Martin-De Las Heras S, Valenzuela A, Overall CM. The matrix metalloproteinase gelatinase A in human dentine. Archives of Oral Biology. 2000;45:757-765.

7. Bedran-Russo AKB, Pereira PN, Duarte WR, et al. Application of crosslinkers to dentin collagen enhances the ultimate tensile strength. $J$ Biomed Mater Res B Appl Biomater. 2007;80(1):268-272.

8. Tay FR, Pashley DH. Biomimetic remineralization of resin-bonded acidetched dentin. J Dent Res. 2009;88(8):719-724.

9. Hosaka K, Nishitani Y, Tagami J, et al. Durability of resin-dentin bonds to water-vs. ethanol-saturated dentin. J Dent Res. 2009;88(2):146-151.

10. Gendron R, Grenier D, Sorsa T, et al. Inhibition of the activities of matrix metalloproteinases 2, 8, and 9 by chlorhexidine. Clin Diagn Lab Immunol. $1999 ; 6(3): 437-439$.

11. Loguercio AD, Hass V, Gutierrez MF, et al. Five-year effects of chlorhexidine on the in vitro durability of resin / dentin interfaces. $J$ Adhes Dent. 2016;18(1):35-42.

12. Han-sol Cha, Shin DH. Antibacterial capacity of cavity disinfectants against Streptococcus Mutans and their effects on shear bond strength of a self-etch adhesive. Dent Mater J. 2016;35(1):147-152.

13. Matthijs S, Adriaens PA. Chlorhexidine varnishes: a review. J Clin Periodontol. 2002;29(1):1-8.

14. Collins JR, Olsen J, Cuesta A, et al. In vitro microbiological analysis on antibacterial, anti-inflammatory, and inhibitory action on matrix metalloproteinases- 8 of commercially available chlorhexidine digluconate mouth rinses. Indian J Dent. 2018;29(6):799-807.
15. Brackett WW, Tay FR, Brackett MG, et al. The effect of chlorhexidine on dentin hybrid layers in vivo. Oper Dent. 2007;32:107-111.

16. Carrilho MRO, Carvalho RM, De Goes MF, et al. Chlorhexidine preserves dentin bond in vitro. J Dent Res. 2007;86:90-94.

17. Carvalho RMD, Carrilho MDO, Pereira LCG, et al. Adhesive systems: fundamentals for clinical application. Rev Biodonto. 2004;2:1-89.

18. Ercan E, Özekinci T, Atakul F, et al. Antibacterial activity of $2 \%$ chlorhexidine gluconate and 5.25\% sodium hypochlorite in infected root canal: in vivo study. J Endod. 2004;30:84-87.

19. Perdigao J, Denehy GE, Swift Jr EJ. Effects of chlorhexidine on dentin surfaces and shear bond strengths. Am J Dent. 1994;7(2):81-84.

20. Kuyyakanond T, Quesnel LB. The mechanism of action of chlorhexidine. FEMS Microbiology Letters. 1992;100(1-3):211-215.

21. de Castro FLA, de Andrade MF, Júnior SLLD, et al. Effect of $2 \%$ chlorhexidine on microtensile bond strength of composite to dentin. Journal of Adhesive Dentistry. 2003;5(2):129-138.

22. Zheng $\mathrm{P}$, Chen H. Evaluate the effect of different mmps inhibitors on adhesive physical properties of dental adhesives, bond strength and mmp substarte activity. Sci Rep. 2017;7(1):4975.

23. Ricci HA, Sanabe ME, Costa CA, et al. Effect of chlorhexidine on bond strength of two-step etch-and-rinse adhesive systems to dentin of primary and permanent teeth. Am J Dent. 2010;23(3):128-132.

24. Stanislawczuk R, Amaral RC, Zander-Grande C, et al. Chlorhexidinecontaining acid conditioner preserves the longevity of resin-dentin bonds. Oper Dent. 2009;34(4):481-490.

25. Sabatini C. Effect of a chlorhexidine-containing adhesive on dentin bond strength stability. Oper Dent. 2013;38:609-617.

26. Lamiaa-Mahmoud M, Haidy-Nabil S, Hanaa-Mahmoud E. The effect of incorporating different concentrations of chlorhexidine digluconate on the degree of conversion of an experimental adhesive resin. $J$ Clin Exp Dent. 2018;10(4):371-377.

27. Araújo MDSRG, Souza LCD, Apolonio FM, et al. Two-year clinical evaluation of chlorhexidine incorporation in two-step self-etch adhesive. J Dent. 2015;43(1):140-148.

28. Palosaari H, Pennington CJ, Larmas M, et al. Expression profile of matrix metalloproteinases (MMPs) and tissue inhibitors of MMPs in mature human odontoblasts and pulp tissue. Eur J Oral Sci. 2003;111(2):117-127.

29. Tersariol IL, Geraldeli S, Minciotti CL, et al. Cysteine cathepsins in human dentin-pulp complex. J Endod. 2010;36(3):475-481.

30. Hiraishi N, Yiu CKY, King NM, et al. Effect of 2\% chlorhexidine on dentin microtensile bond strengths and nanoleakage of luting cements. $J$ Dent. 2009;37(6):440-448. 